\title{
O BRASIL E O VÁCUO DE LIDERANÇA REGIONAL: 0 AVANCุO SINO-AMERICANO (2011/2016)
}

\author{
Corival Alves do Carmo ${ }^{1}$ \\ Cristina Soreanu Pecequilo ${ }^{2}$
}

\section{Introdução}

De 2003 a 20IO, as relações internacionais do Brasil apresentaram uma ação de alto perfil, a partir da combinação dos eixos de Cooperação NorteSul e Sul-Sul, com ênfase na segunda dimensão. Esta ênfase foi sintetizada em uma dinâmica de projeção sistemática das iniciativas em nível regional e global, a partir de uma agenda focada em temas como desenvolvimento, projetos sociais, redução de assimetrias e reforma das instituições multilaterais, readequando-se ao novo equilíbrio de poder mundial em formação.

A construção de alianças de geometria variável com as nações emergentes, a retomada de uma presença mais sólida na África, Ásia e Oriente Médio, o maior investimento político-econômico em países de menor desenvolvimento relativo e uma postura reivindicatória nos principais fóruns internacionais, compuseram a agenda da diplomacia "ativa e altiva" (Amorim 20I5) do Embaixador Celso Amorim, então Ministro das Relações Exteriores do governo de Luis Inácio Lula da Silva.

Na América do Sul, a reconfiguração significou a continuidade de projetos de integração existentes como o Mercado Comum do Sul (MERCOSUL) e a Integração da Infraestrutura Regional Sul-Americana (IIRSA) e o lançamento de novas estruturas: em 2007, a União de Nações Sul-Ameri-

\footnotetext{
I Professor Adjunto de Relações Internacionais da Universidade Federal de Sergipe. E-mail: corival@gmail.com

2 Professora Adjunta de Relações Internacionais da UNIFESP (Universidade Federal de São Paulo) e Pesquisadora Associada NERINT/UFRGS e UNIFESP/UFABC. E-mail: crispece@ gmail.com
} 
canas (UNASUL) e, em 20I0, a Comunidade de Estados Latino-Americanos e Caribenhos (CELAC). Procurou-se fortalecer a região como plataforma de inserção global, a partir da criação de mecanismos de negociação interregionais como as Cúpulas América do Sul-Países Árabes e América do Sul-África (ASA) e parcerias com nações do Sul (China e o Fórum-China-CELAC) e do norte (a União Europeia, o Japão).

A busca de alternativas às relações com os Estados Unidos e a redução da vulnerabilidade político-econômica diante da potência hegemônica foram o pano de fundo. Favorecendo esta dinâmica, incluía-se o recuo regional norte-americano (Pecequilo 20I3), resultante de sua presença na Eurásia no contexto da Guerra Global Contra o Terror (GWT) iniciada em 200I, depois dos atentados de ir de Setembro de 200I no território continental, e as operações no Afeganistão (200I/20I4) e no Iraque (2003/20II). Tanto para o Brasil quanto para os demais emergentes este foi um momento de expansão, com o redimensionamento de suas parcerias e interesses regionais e globais, aproveitando o vácuo norte-americano e as potencialidades destas nações, reforçando o processo de desconcentração de poder em andamento (Visentini 2013).

Todavia, a partir de 20II, no caso brasileiro, a substituição desta agenda de alto por uma de baixo perfil, devido à troca de governo de Lula para o de Dilma Rousseff (20II/20I6), trouxe um ponto de inflexão a estes projetos. $\mathrm{Na}$ América do Sul, a ausência de liderança brasileira reflete em um aumento da presença da China e a contrarreação dos Estados Unidos.

Para avaliar este contexto, este artigo encontra-se dividido em três partes: uma análise da política externa do Brasil e sua agenda na América do Sul, a projeção da China e a dos Estados Unidos neste espaço geopolítico e geoestratégico. Busca-se, portanto, apresentar um panorama deste momento estratégico, assim como algumas perspectivas desta triangulação.

\section{O Brasil e a América do Sul: Avanço e Retrocesso}

A trajetória contemporânea da integração para o Brasil tem três etapas chave: a sul-americanização da política externa na década de I970, a criação do MERCOSUL nos anos I990 e o lançamento da IIRSA em 2000. Todas estas etapas compõem o processo de valorização da América do Sul como plataforma de projeção internacional, que culmina nas iniciativas pós-2003, com a ascensão da administração Lula.

Isso não significa afirmar que antes destas etapas não tenham havido propostas regionais do Brasil para a América do Sul ou agendas prévias de 
integração, vide o caso da Operação Panamericana de Juscelino Kubistchek (I958), a Associação Latino-Americana (ALAC) de i960 ou a Associação Latino-Americana de Integração (ALADI) na década de I980. Porém, indica que os investimentos político-econômicos e estratégicos nestas oportunidades anteriores pelo Brasil e parceiros não detiveram aprofundamento e continuidade para mudar o perfil de seu relacionamento intrarregional. Em contrapartida, no século XXI observou-se relativa maior solidez dos arranjos, mas que sofrem retrocesso no pós-20II.

Brevemente mencionando estas três etapas, a sul-americanização da política externa corresponde a uma ação da política externa do Regime Militar (1964/1985) de fortalecer a base regional do Brasil a partir de uma redução de conflitos. O objetivo era minimizar o nível de insegurança das fronteiras brasileiras, em particular no Cone Sul, relativizando os custos das relações com países como a Argentina, tradicionalmente vistas como fonte de ameaça. Outra dimensão era a fronteira Norte, devido às ameaças à soberania nacional representadas pela baixa ocupação político-econômica-social e a crescente relevância das questões ambientais que opunha os países amazônicos às nações desenvolvidas na disputa entre conservacionismo e desenvolvimento sustentável. A unidade desta região e o seu crescimento e ocupação eram percebidas como fundamentais para impedir a ingerência de potências externas.

A segunda etapa corresponde a um momento de transformação destas condições internas e externas que levam à crise econômica (década perdida), às incertezas da redemocratização e o "aquecimento" da bipolaridade, promovido pelos Estados Unidos de Ronald Reagan (I98I/I988) que culmina com o fim da Guerra Fria em i989. O que se observa é um fechamento de espaços globais e a maior relevância das dinâmicas regionais. A reaproximação bilateral com a Argentina corresponde à primeira fase desta agenda, a qual se agrega a criação do MERCOSUL nos anos I990, com a adesão de Paraguai e Uruguai.

A década de 1990 foi paradoxal para os processos de integração, por trazer dimensões de alinhamento e autonomia associados a sua consolidação. Em um primeiro momento, o alinhamento foi predominante devido ao encerramento da bipolaridade e a retomada de uma ofensiva hemisférica por parte dos Estados Unidos. Tanto o Brasil quanto a América Latina viram-se confrontados com a continuidade da perda de espaços internacional e a crise econômica. A ambos se agregaram pressões para a adesão ao neoliberalismo político-econômico.

O neoliberalismo, sintetizado no Consenso de Washington, possui forte interdependência com a ofensiva hemisférica estadunidense que apa- 
rentemente traria a quebra desta perda de relevância. Entretanto, o que se pode observar foi apenas a apresentação de uma pauta de condicionalidades e promessas, associadas a esta ofensiva. Entretanto, do lado do Brasil e dos demais países latino-americanos isso resultou em uma adesão.

O projeto norte-americano era composto de três pilares: primeiro, o já mencionado Consenso de Washington, organizado em torno das prioridades de redução do papel do Estado, abertura comercial, desregulamentação e privatização, corte de gastos sociais, câmbio flexível; segundo, a integração regional, com destaque à proposta da criação de uma Zona Hemisférica de Livre Comércio (a Iniciativa para as Américas) e o Acordo de Livre Comércio da América do Norte Estados Unidos, Canadá e México (NAFTA) e a visão da segurança compartilhada, com ênfase na desmilitarização da região, na agenda coletiva e transnacional para lidar com temas como meio ambiente, direitos humanos, tráfico de drogas e imigração, boa governança e democracia.

Neste momento, chegou-se a anunciar o fim da Doutrina Monroe, e o início de uma era de cooperação hemisférica inédita entre os Estados Unidos e seus vizinhos. O slogan "trade, not aid" tornou-se simbólico destes novos tempos, e do reengajamento norte-americano em sua zona de influência. Contudo, a imagem da renovação contrastava com uma realidade de continuidade: não houve reformas no sistema interamericano, sustentado no Tratado Interamericano de Assistência Recíproca (TIAR I947) ou na Organização dos Estados Americanos (OEA I948) e se manteve o embargo econômico à Cuba e o rompimento das relações diplomáticas.

Apesar de seu conteúdo autonomista, neste contexto o MERCOSUL foi apresentado pelos recém-empossados governos de Fernando Collor de Mello (I992/1994) e Carlos Menem (I989/1999) como um complemento à Iniciativa para as Américas. A saída de Collor do poder levaria à relativização dos alinhamentos no caso do Brasil, e o foco na integração sul-americana como objetivo estratégico, o que se estendeu às gestões de Itamar Franco (I992/I994) e de Fernando Henrique Cardoso (I995/2002). Itamar chegou a propor a criação de uma Área de Livre Comércio Sul-Americana (ALCSA) em I994, em contraposição à retomada da iniciativa estadunidense, a Área de Livre Comércio das Américas (ALCA).

A marca da política externa de Cardoso foi a da ambiguidade. Inicialmente, a mesma priorizou a "autonomia pela integração" com maior aproximação aos Estados Unidos, a retomada do Consenso de Washington e a valorização das relações Norte-Sul. Esta priorização, entretanto, não significou o abandono do MERCOSUL ou concessões aos Estados Unidos nas negociações da ALCA, o que rendeu a FHC inúmeras críticas de setores pró-americanos. Foi a partir desta resistência (e de outras em arenas multilaterais como 
a OMC) que se atribuiu ao Brasil o fracasso da ALCA quando, na realidade, o processo se esvaziou mutuamente.

As ofensivas norte-americanas são cíclicas, somente ocorrem quando existe uma percepção de ameaça a seus interesses regionais ou oportunidades a perseguir, e esse havia sido o caso em I989/1990 quando da apresentação das primeiras propostas. Embora se falasse no nascimento de um cenário unipolar, para os Estados Unidos a realidade era outra: a do declínio relativo em meio à crescente multipolaridade trazida pela ascensão do eixo Europa-Ásia, com a expansão da União Europeia e do Japão (depois a China) e a necessidade de garantir um mercado de reserva para as exportações norte-americanas em declínio. Os Estados Unidos apenas procuravam sem grandes esforços ou investimentos preservar sua zona de influência, desengajando-se com a redução das ameaças intra e extrarregionais e com o surgimento de outros cenários mais relevantes (tradicionalmente focados na Eurásia). Este fenômeno serve de pano de fundo para o século XXI e para a crise da América Latina, assim como para o vácuo de poder estadunidense que se acentua neste período.

Inaugura-se a terceira etapa da integração, iniciada pelo lançamento da IIRSA em 2000, no governo de FHC. A IIRSA representa a prevalência da autonomia nas agendas sul-americanas e a preocupação com a retomada do ciclo de desenvolvimento. Esta retomada era percebida como essencial para que os países pudessem superar a crise gerada pelo neoliberalismo e pelas opções políticas de alinhamento aos Estados Unidos. O salto qualitativo foi representado pela prioridade ao setor de infraestrutura para alavancar as dinâmicas de crescimento, reativando as economias e aproveitando suas vantagens comparativas e complementaridades.

Pode-se dizer que a IIRSA foi a primeira oportunidade na qual os países sul-americanos elaboraram uma percepção sistêmica sobre seu espaço regional, identificando vulnerabilidades, zonas de risco e oportunidades. Mais do que um discurso pró-unidade para fortalecer a região, a IIRSA era o lado pragmático e realista deste fortalecimento, com a elaboração de projetos concretos e o estabelecimento de meios para o seu financiamento (como os recursos do Banco Nacional de Desenvolvimento, do Banco Interamericano de Desenvolvimento e do FONPLATA).

Este é um momento no qual prevalece um distanciamento e um vácuo de poder norte-americanos significativos, em contraposição à ofensiva do início dos anos I990. Isso favorece o desenvolvimento de propostas autônomas, nas quais os Estados Unidos não se encontram inserido: são agendas autóctones e com foco nos interesses e na melhoria das condições sul-americanas. 
Esta autonomia não deriva apenas da IIRSA, mas da emergência do "Socialismo do Século XXI" de Hugo Chávez na Venezuela. Tal distanciamento em 2000 resulta da realização de eleições presidenciais nos Estados Unidos, e a reação do governo Clinton é a concretização da Iniciativa Andina Contra as Drogas (Plano Colômbia) como parte de um processo de militarização da América do Sul e reposicionamento estratégico. Em 200I, esta postura deriva dos atentados de II/o9, da GWT e das subsequentes operações militares (e no quadro da GWT, a América do Sul foi foco de preocupação com a Tríplice Fronteira Brasil, Argentina, Paraguai).

Ainda que em 2000, o candidato republicano George W. Bush, depois eleito presidente, tenha mencionado que sua gestão traria um "Século das Américas” com ênfase na cooperação, as propostas hemisféricas, como a ALCA, foram colocadas em segundo plano. O perfil unilateral militarista de W. Bush colocava em xeque o multilateralismo em geral, em particular o econômico e abria espaço para outras nações exercerem influência neste campo.

Nas Américas, as ações ficaram restritas até 2007 a tentativas tímidas e de baixo custo de engajamento como os Tratados de Livre Comércio (TLCs) com países de menor peso relativo na região com os quais os norte-americanos já possuíam forte interdependência como Chile, Peru, Colômbia e Panamá. Cronologicamente, estes TLCs entram em vigor em 2004, 2009, 2011 e 20I2, e são acompanhados por uma negociação adicional com os países da América Central. Esta negociação resulta em 2007 na criação do CAFTA (Acordo de Livre Comércio da América Central-EUA). Para o Brasil, foi instituído o Diálogo Estratégico em 2005, solidificando as estruturas existentes, mas sem maiores avanços políticos-econômicos (a maior relevância era reconhecer o poder do Brasil como potência regional e global). Em 2007/2008 a crise econômica global, com foco nos Estados Unidos e na União Europeia, deu continuidade a este processo de distanciamento.

Havia, portanto, espaço para o crescimento e expansão da IIRSA. A IIRSA era composta pelos Eixos de Integração e Desenvolvimento (EID) e pelos Projetos Setoriais de Integração (PSI). Em termos de EIDs, foram apresentados dez: Eixo Andino, Eixo Andino do Sul, Eixo de Capricórnio, Eixo da Hidrovia Paraguai-Paraná, Eixo do Amazonas, Eixo do Escudo Guianés, Eixo do Sul, Eixo Interoceânico Central, Eixo MERCOSUL-Chile e Eixo Peru-Brasil-Bolívia. Por sua vez, os PSI eram: Instrumentos de Financiamento de Projetos de Integração Física Regional, Integração Energética, Facilitação de Trocas nas Fronteiras, Tecnologias de Informação e Comunicações, Sistemas Operacionais de Transporte Aereo, Sistemas Operacionais de Transporte Marítima e Sistemas Operacionais de Transporte Multimodal. 
A entrada do século XXI e a ascensão do novo governo brasileiro com Lula manteve esta dinâmica, e a consolidação de uma visão estratégico-política associada à IIRSA. Em 2004, a proposta da CASA representou esta ação, ao agregar um discurso de Cooperação Sul-Sul e projeção internacional da região. A criação das Cúpulas ASPA e ASA, já mencionadas, faz parte deste processo, assim como de retomada da visão globalista. Tal visão recupera o Terceiro Mundismo e a amplia as coalizões de geometria variável como o Fórum IBAS (Índia, Brasil, África do Sul), os BRICS (Brasil, Rússia, Índia, China e África do Sul). A retomada das políticas africana, no Oriente Médio e asiáticas, com foco nas relações bilaterais com a China compõe esta agenda.

Estas iniciativas abrem alternativas, e elevam a importância da América do Sul como espaço geopolítico e geoeconômico, mas também de seu entorno como o Atlântico Sul (a "Amazônia Azul”). Estrategicamente, a Amazônia Azul é relevante zona de passagem entre as Américas, a África e a Ásia, como região rica em recursos energéticos como petróleo (em particular o pré-sal e o gás).

No que se refere à IIRSA, a partir de 2005, com a Agenda de Implementação Consensuada (AIC), os primeiros projetos começaram a sair do papel, com alguns já tendo sido concluídos, como se pode verificar na tabela abaixo

\section{Tabela 1- $\mathrm{AlC}^{3}$}

\begin{tabular}{|c|c|c|c|c|c|}
\hline No & \multicolumn{1}{|c|}{ Projetos } & Eixo & $\begin{array}{c}\text { Milhões } \\
\text { US\$ }\end{array}$ & Países & Situação \\
\hline $\begin{array}{l}\text { Duplicação da Rodovia 14 } \\
\text { entre Paso de lós Libres e } \\
\text { Gualeguaychú }\end{array}$ & $\begin{array}{c}\text { MERCOSUL- } \\
\text { Chile }\end{array}$ & 780,0 & AR (BR) & Concluído \\
\hline $\begin{array}{l}\text { Adequação do Corredor } \\
\text { Rio Branco-Montevidéu- } \\
\text { Colônia-Nueva Palmira } \\
\text { Construção da Ponte }\end{array}$ & $\begin{array}{c}\text { MERCOSUL- } \\
\text { Chile }\end{array}$ & 234,0 & $\begin{array}{c}\text { UR (AR- } \\
\text { BR) }\end{array}$ & Concluído \\
\hline $3 \begin{array}{l}\text { Internacional Jaguarão- } \\
\text { Rio Branco } \\
\text { Duplicação do Trecho }\end{array}$ & $\begin{array}{c}\text { MERCOSUL- } \\
\text { Chile }\end{array}$ & 35,0 & BR-UR & $\begin{array}{c}\text { Pré- } \\
\text { Execução }\end{array}$ \\
\hline $\begin{array}{l}\text { Palhoça-Osório (Rodovia } \\
\text { Mercosul) }\end{array}$ & $\begin{array}{c}\text { MERCOSUL- } \\
\text { Chile }\end{array}$ & 700,0 & $\begin{array}{c}\text { BR (AR- } \\
\text { UR) }\end{array}$ & Execução \\
\hline
\end{tabular}

3 Elaborada a partir dos documentos oficiais da IIRSA, Agenda de Projetos Prioritários de Integração, dos anos 2011 e 2013. 
Projeto Ferroviário Los

5 Andes-Mendoza (Estrad de Ferro Transandina Central)

MERCOSULChile

$5.1000,0 \quad$ AR-CH PréRodovia Internacional

6 60- CH (Setor ValparaísoAndes)

7 Gasoduto do Nordeste Argentino

\section{Chile}

MERCOSULChile

286,

$\mathrm{CH}(\mathrm{AR})$ Concluído

MERCOSULChile

$1.000,00$

AR (BO) Execução

Construção da Ponte

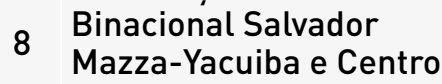

Capricórnio de Fronteira

Nova Ponte Presidente

9 Franco-Porto Meira, com Centro de Fronteira Paraguai-Brasil

Construção da Rodovia

10 Pailón-Śan José-Porto

Suarez

Anel Ferroviário de São

11 Paulo (Trecho Norte-Sul e Sull

Capricórnio 23,0 AR-BO $\begin{gathered}\text { Pré- } \\ \text { Execução }\end{gathered}$

Interoceânico Central

Interoceânico Central

80,0 PA-BR $\begin{gathered}\text { Pré- } \\ \text { Execução }\end{gathered}$

Passo de Fronteira

12 Infante Rivarola-CanãdaOruro

Interoceânico Central

477,0
BO (BR-
$\mathrm{CH})$

Construção da Rodovia

Canãda Oruro-

13 Villamontes0TarijaEstación Albaroa (1 ${ }^{a}$ Fasel

14 Rodovia Toledo-Pisiga

Interoceânico Central

850,0 BR $\begin{gathered}\text { Pré- } \\ \text { Execução }\end{gathered}$

Interoceânico Central

2,0 BO-PA Concluído

Pavimentação e Melhoria

15 as Rodovia IquiqueColchane

Interoceânico Central

49,0 BO (PA) Concluído

16 Recuperação do Trecho Interoceânico El Siliar

Central

95,0 BO (CH) Concluído Centro Binacional de

17 Atendimento de Fronteira Desaguadero

Andino

Paso de Fronteiras

18 Cúcuta-San Antonio Del Táchira

Andino

42,0 $\mathrm{CH}$ (BO) Concluído 120,0 BO (CH- Concluído 7,5 BO-VE $\begin{gathered}\text { Pré- } \\ \text { Execução }\end{gathered}$ 2,0 CO-VE $\begin{aligned} & \text { Perfil de } \\ & \text { Estudos }\end{aligned}$ 
Recuperação da

19 Navegabilidade do Rio Meta

20 Corredor Viário TumacoPasto-Mocoa-Puerto-Asis Andino $\quad 108,0$ CO-VE Execução Rodovia Paita-Tarapoto-

21 Yurimagas, Portes e Centros Logísticos

Rodovia Lima-Tingo

22 Maria-Pucalipa, Portos e Amazonas 1.351,3 PE (BR) Execução Centros Logísticos

23 Porto Francisco de Orellana Amazonas $\quad 373,0 \quad$ CO Execução Amazonas 681,2 PE (BR) Execução Pavimentação Iñapari-

24 Porto MaldonadoInambari, InambariJuliaca/Inambari-Cusco

25 Ponte Sobre o Rio Acre Rodovia Boa Vista-

26 Bonfim-LethemGeorgetown

27 Ponte sobre o Rio Takutu Rodovia Venezuela

28 (Cidade Guiana)-Guiana (Paramaribo

\begin{tabular}{|c|c|c|}
\hline Amazonas & 105,3 & $\mathrm{EQ}$ \\
\hline
\end{tabular}

Peru-Brasil-
Bolívia
$1.384,0$ PE (BR) Concluído

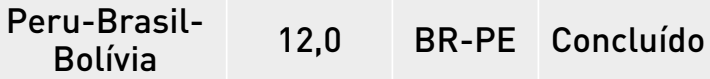

$\begin{array}{lll}\text { Escudo } & 3,3 \quad \text { GU-BR Concluído } \\ \text { Guianês }\end{array}$

\begin{tabular}{l|l|l|l} 
Escudo & 10,0 & GU-BR & Concluído \\
Guianês &
\end{tabular}

$\begin{array}{llcl}\text { Escudo } & 0,8 & \text { VE-GU- } & \text { Perfil de } \\ \text { Guianês } & \text { SU } & \text { Estudos }\end{array}$
Melhoras na Via Nieuw Nickerire-Paramaribo-

29 Albina e Cruzamento Internacional sobre o Rio \begin{tabular}{l|l|l} 
Escudo & 105,0 & SU-GU \\
Guianês & Execução
\end{tabular} Marowijne Exportação por

30 Remessas Postais para PMEs TICs $\quad 5,0$ Regional Execução Implantação do Acordo

31 de Roaming na América do Sul

Em 2007 isso resultou na renomeação da CASA como UNASUL, e a introdução de novos arranjos como a CELAC, criada em 20Io. Dentre os projetos da UNASUL destaca-se o estabelecimento de um Conselho de Defesa 
Sul-Americano (CDS). Estas iniciativas CDS e CELAC representam a consolidação de novos esforços de autonomia e liderança.

O CDS, e a preocupação com o desenvolvimento de um pensamento estratégico para a América do Sul refletem a retomada da preocupação regional com temas que haviam ficado em segundo plano no imediato pós-Guerra Fria: a autonomia no campo da segurança e defesa, o investimento nestes setores, a preservação da soberania e a não-ingerência. Esta iniciativa oferece um contraponto às ações norte-americanas no setor, que oscilam entre demandar uma postura minimalista das nações locais e aumentar sua presença física na região, seja justificada pela guerra contra as drogas, seja pelas ameaças do terrorismo transnacional.

A CELAC consiste-se em um projeto de integração que ampliou a projeção brasileira em uma zona tradicional de interesse dos Estados Unidos, a América Central e o Caribe (sempre vistos como "quintal norte-americano"). Além da construção deste arcabouço regional, em 20Io, o Brasil também se encontrou envolvido na crise do regime político de Honduras, criticando a deposição do governante eleito Manuel Zelaya, a quem concedeu asilo. Adicionalmente, o país ampliou suas ações em Cuba, agregando ao tradicional apoio político, medidas mais concretas como a construção do Porto de Mariel inaugurado em 20I5. Este Porto é uma importante ligação logística entre as Américas e as regiões do Pacífico, América do Norte e União Europeia e o Atlântico Sul. Igualmente, a CELAC tornou-se, a partir de 20I4, ponto de apoio para o fórum China-CELAC.

Percebe-se que até 2010 havia um avanço crescente nas ações sul-americanas e um clima de otimismo no futuro da região, superando sua marginalização e crise no pós-Guerra Fria. A crescente presença da China ajudava a expansão econômica local, por meio da exportação de commodities agrícolas, energéticos e minérios, enquanto os Estados Unidos mantinham-se distantes e com perda de influência gradual.

A partir de 20II, a mudança relativa de vetor da política externa do Brasil com a administração de Dilma Rousseff iniciou um período de retrocesso e vácuo de poder nesta presença sul-americana. Em termos retóricos, até pela continuidade de um governo do Partido dos Trabalhadores, que capitalizou os sucessos da Era Lula, a expectativa era de que se mantivessem os projetos. Tanto na retórica quanto na prática este pareceu ser o caso em 20II, havendo até uma percepção de adensamento no que se refere à UNASUL e a incorporação da IIRSA, com a criação do Conselho Sul Americano de Infraestrutura e Planejamento (COSIPLAN).

Entretanto, o que prevaleceu foi um esvaziamento do campo das relações internacionais do Brasil, regional e global. Mas em que se consistiu 
este esvaziamento e mudança de vetor? Quais os resultados deste recuo?

Em contraste com o período 2003/2010, o primeiro mandato de Dilma Rousseff caracterizou-se por uma atuação de baixo perfil. Esta atuação era composta por um menor exercício da diplomacia presidencial por Rousseff, tanto nos fóruns regionais quanto globais, como por uma tentativa de reduzir ruídos e se aproximar dos Estados Unidos para contemplar a pressão da oposição interna. Alguns eventos que sintetizam esta dinâmica foram a visita, já em Março de 20II, do Presidente Obama ao Brasil, e a ampliação do Diálogo Estratégico, e o crescente foco nas negociações MERCOSUL-União Europeia.

Deve-se destacar que esta visita ocorre também no contexto de perda contínua de espaço dos Estados Unidos na América Latina para a China. Em 20Io, a China tornou-se, no caso do Brasil, o maior parceiro individual do país, superando os Estados Unidos, vide a Tabela 2.

Tabela 2 - 0 Intercâmbio Comercial: Brasil, EUA e China (US\$ FOB)

\begin{tabular}{|c|c|c|c|}
\hline Ano & Exportação & Importação & Saldo \\
\hline \multirow{2}{*}{03} & $16.728 .079 .047(22,85 \%)$ & $9.569 .454 .702(19,80 \%)$ & 7.158.624.345 \\
\hline & 4.533.363.162 (6,19\%) & $2.147 .801 .000(4,44 \%)$ & 2.385 .562 .162 \\
\hline \multirow{2}{*}{006} & $24.524 .748 .523[17,8$ & $14.657 .479 .678(16,05$ & 9.867 .268 .845 \\
\hline & $8.402 .368 .827(6,10 \%)$ & $7.990 .448 .434(8,75 \%)$ & 411.920 .393 \\
\hline \multirow{2}{*}{2010} & 19.307.295.562 (9,56\%) & $27.044 .361 .398(14,88 \%)$ & -7.737 .065 .83 \\
\hline & $30.785 .906 .442(15,25 \%)$ & $25.995 .419 .005(14,08 \%)$ & 5.190 .487 .437 \\
\hline \multirow{2}{*}{201} & $27.027 .771 .514(12,01 \%)$ & $35.018 .330 .949(15,28 \%)$ & -7.990 .559 .43 \\
\hline & $40.616,107.929(18,04 \%)$ & $37.344 .985 .579(16,30 \%)$ & 3.271 .122 .350 \\
\hline \multirow{2}{*}{015} & $24.079 .945 .544(12.60 \%)$ & $26.471 .345 .593(15,44 \%)$ & -2.391 .400 .04 \\
\hline & $35.607 .523 .612(18,63 \%)$ & $30.719 .405 .022(17,92 \%)$ & 4.888.118.590 \\
\hline
\end{tabular}

Obs. Dados da China em Itálico

Fonte: Dados MDIC (2015/2016)

Este era um fato inédito nas relações bilaterais e não se restringia a ela na região: em vários países sul-americanos a China ganhara terreno, tornando-se a primeira, segunda ou terceira parceira comercial, mesmo em nações 
de tradicional alinhamento com os Estados Unidos como o Chile que, desde 2004, detinha um TLC com os norte-americanos (como indicado na Tabela 3).

Tabela 3 - A Expansão Comercial da China

\begin{tabular}{|l|c|c|c|c|}
\hline País & \multicolumn{2}{c|}{$\begin{array}{c}\text { China Como Destino de } \\
\text { Exportações }\end{array}$} & \multicolumn{2}{c|}{$\begin{array}{c}\text { China Como Origem de } \\
\text { Importações }\end{array}$} \\
\hline Argentina & 2000 & 2014 & 2000 & 2014 \\
\hline Brasil & 6 & 2 & 4 & 2 \\
Chile & 12 & 1 & 11 & 1 \\
Colômbia & 5 & 1 & 4 & 2 \\
\hline Venezuela & 36 & 1 & 9 & 2 \\
\hline
\end{tabular}

Fonte: Dados CEPAL, 2016 - Elaborada Pelos Autores

Havia, portanto, uma pressão dupla sobre a hegemonia, vinda do Brasil e da China em sua zona de influência preferencial que, no pós-20II, passou a sofrer algumas mudanças. A triangulação estratégica Brasil-Estados Unidos-China parece cada vez mais tornar-se uma bipolaridade Estados Unidos-China. Afinal, De 20II a 20I4, os projetos sul-americanos caminharam, mas em ritmo lento, e passaram a ser afetados pela realidade da instabilidade política e da crise econômica brasileira. No que se refere à economia, na verdade toda região passou a sentir certo recuo devido à diminuição da demanda chinesa por commodities. Os investimentos no COSIPLAN foram significativamente reduzidos, levando à suspensão de estudos de projetos e atrasos em obras em andamento. Adicionalmente, a atuação brasileira regional e global tendeu a se mostrar cada vez mais apolítica, reduzindo o conteúdo estratégico das relações internacionais a ações comercialistas.

A inconsistência se colocou na agenda externa: se a aproximação com os norte-americanos foi uma prioridade da gestão Dilma no início, a partir de 2013 a mesma foi substituída por conflito devido ao caso de espionagem da Agência de Segurança Nacional dos Estados Unidos (NSA) denunciada por Edward Snowden, e na sequência por estagnação, mesmo com a visita da Presidente a este país em 2015. Definida como "visita de trabalho" a ida de Dilma a Washington visava minimizar as crises geradas pelo cancelamento da "visita de Estado" em 20I3.

Esta situação somente se agravou a partir de 2015, com aprofundamento até Maio de 20I6, a luz das acusações de corrupção e o encaminhamento do processo de impeachment. Com isso, opôs-se a uma década de avanço, uma sequência de retrocessos, cujas consequências são além da perda 
de espaço e liderança, o aumento da instabilidade regional, o esvaziamento dos projetos de integração, a consolidação da presença da China na América do Sul e o aprofundamento da contrarreação hegemônica estadunidense. Iniciados mesmo antes do fim do governo Lula, estes movimentos intensificaram-se no pós-20II no vácuo de poder brasileiro.

\section{A Ação da China}

Gilberto Freyre em alguns trabalhos referiu-se ao Brasil com um termo bastante curioso "China tropical", porque no seu entender, como a China, além do tamanho territorial, o Brasil possuía "poder de absorção cultural" e alguns traços culturais orientais. E ao analisar o comportamento dos Estados Unidos afirmou que este país deveria olhar mais para a América do Sul, e particularmente, em relação ao Brasil afirmou:

Especialmente para a China tropical - o Brasil - que aqui começa a se definir como meia potência, enquanto a outra China se vem afirmando vigorosamente como potência. Duas Chinas cuja presença no mundo moderno tende a se tornar cada vez mais significativa. (Freyre 20II, 20I)

No mesmo artigo, originalmente publicado em I959, escreveu

A impopularidade dos Estados Unidos na América Latina talvez derive, em grande parte, do fato de o "colosso norte-americano", como por vezes os latino-americanos chamam àquela nação, ser, aos seus olhos, um grande poder praticamente sem competidores (...). (Freyre 20II, I87)

De fato, 50 anos depois da publicação deste texto algumas mudanças pareciam reforçar aspectos da primeira citação e alterar o cenário retratado na segunda. Ao final da primeira década do século XXI, o Brasil era apontado ao lado da China como uma das potências emergentes no sistema internacional. Paralelamente, via-se a ampliação da influência do Brasil na América do Sul e uma crescente presença econômica chinesa, enquanto havia um refluxo relativo dos Estados Unidos. De 2010 para 20I6, houve modificações significativas. Os problemas econômicos internos acabaram por enfraquecer a política externa brasileira para a América do Sul, enquanto a China aprofundou a construção de uma política externa para reforçar os vínculos econômicos com a região. E os Estados Unidos iniciaram a sua reação.

O principal aspecto da mudança da política externa da China para a América Latina e Caribe foi o citado Fórum China-CELAC. Em primeiro lugar, 
a criação do Fórum representou a inserção da região no modelo de política externa e cooperação estabelecido com a África com o Fórum China-África em 2000. Em segundo, faz com que as relações da China com a região saiam do plano prioritariamente comercial para ganhar um caráter mais político e estratégico na medida em que os projetos a serem financiados pelos chineses estão em consonância com as necessidades de abastecimento da economia da China. Do mesmo modo que na África, a China não impõe condicionalidades de ordem política nos acordos, mas evidentemente os projetos giram em torno de ações que reforçam as vinculações das economias da região com a China, o que acaba por resultar em consequências políticas e estratégicas relevantes.

Como visto, no momento da criação do Fórum, a China era ou o principal parceiro comercial ou o segundo da maior parte dos países da América do Sul. O crescimento econômico, que favoreceu a maior parte dos governos da região desde o início dos anos 2000 , decorreu basicamente da crescente demanda chinesa por commodities, que permitiu o aumento tanto dos volumes exportados quanto dos preços criando um cenário favorável em relação aos termos de troca. Em 2003, a China representava 5,4\% das importações mundiais e em 20I4, I0,5\%, enquanto os Estados Unidos tiveram sua participação reduzida no mesmo período de I6,9\% para I2,9\% (WTO 20I5a). A atratividade chinesa reforçou o caráter de exportadores de produtos primários dos países da região. Mesmo o Brasil, país mais desenvolvido industrialmente na América do Sul, sofreu os efeitos do processo tanto com a primarização das exportações como com o efeito desindustrializante decorrente das dificuldades de concorrer com a produção industrial chinesa pela menor competitividade estrutural das empresas industriais localizadas no Brasil e, conjunturalmente, em função da valorização do real que agravou a situação.

As consequências contraditórias da integração comercial com a China só foram percebidas tardiamente, quando seus efeitos já eram bastante pronunciados. Inicialmente, apenas os aspectos políticos e comerciais favoráveis foram notados, uma menor dependência do mercado dos Estados Unidos e um aumento pronunciado no volume de exportações. Mesmo Chile e Peru, países com acordos de livre comércio com os Estados Unidos, encontraram na China um parceiro econômico mais promissor. Dos maiores países da América Latina, apenas o México foi pouco afetado pela ascensão chinesa, em 20I4, apenas I, $5 \%$ das exportações mexicanas foram destinadas à China, enquanto $80 \%$ foram para os Estados Unidos (WTO 2015b).

A ascensão chinesa também afetou a coesão do projeto integracionista sul-americano. Diante das dificuldades do Brasil em liderar este processo e oferecer alternativas de desenvolvimento, a atratividade da vinculação 
econômica com a Ásia-Pacífico aumentou, especialmente para Chile, Peru, membros da APEC (Cooperação Ásia-Pacífico) desde I994 e I998 respectivamente, e Colômbia, candidata a membro da APEC desde os anos I990. Os três, junto com México, na APEC desde 1993, criaram a Aliança do Pacífico. O ex-presidente peruano, Alan García, um dos impulsionadores do processo, escreveu:

Podemos coexistir con China de manera constructiva y provechosa, conformando grandes bloques de articulación comercial y productiva. La Alianza del Pacífico que integra a Perú, Chile, Colombia y México debe facilitar e impulsar sus servicios e inversiones compartidas, sus exportaciones articuladas en cadenas de valor y la complementación estacional de su agroindustria, orientándose colectivamente hacia los grandes bloques compradores, especialmente a China. (García 2013, I80)

A análise de Alan García evidencia dois aspectos relevantes para a região, um já tratado, a óbvia ascensão da China, e de outro lado, o aspecto mais importante, a necessidade de políticas conjuntas entre os países da região para responder a esta ascensão. O fortalecimento da integração poderia ser uma estratégia para construir uma associação com a China que ao mesmo tempo em que alavanque o crescimento das exportações promova o desenvolvimento. Entretanto, a Aliança do Pacífico dificilmente desempenhará esse papel, considerando a estrutura da economia mexicana, o vínculo mais forte do bloco é com os Estados Unidos. Uma estratégia bem-sucedida, nesse sentido, passaria pela liderança do Brasil, e deveria ser construída através da UNASUL. Mas em nenhum momento a região esteve próxima de um consenso sobre uma estratégia de desenvolvimento articulada com uma visão sobre a forma do relacionamento tanto com a China como com os Estados Unidos.

A criação do Fórum China-Celac reflete a capacidade chinesa de pautar a forma e a agenda das relações com a região, e, portanto, um enfraquecimento relativo do Brasil. Dentro dos BRICS, o Brasil está, em tese, entre iguais, é um tipo de institucionalidade não hierarquizada. O multilateralismo à maneira chinesa presente no Fórum coloca os países da região, e, portanto, também o Brasil, numa posição inferiorizada em relação à China: é um tipo de relação na qual uma parte, a América Latina e o Caribe, faz demandas de ajuda e a outra parte, a China, ocupa a posição do ofertante da ajuda. Ainda que não haja condicionalidades como as tradicionalmente feitas pelas potências ocidentais ou pelo Banco Mundial e o discurso chinês enfatize a lógica horizontal da cooperação Sul-Sul, a relação não deixa de ser hierarquizada. O aporte de recursos pela China evidencia as desigualdades de poder político e econômico. Por exemplo, a conferência do primeiro ministro chinês, Li Ke- 
qiang na Cepal em 20I5:

Específicamente, proponemos explorar el modelo de cooperación "3×3", consistente en la apertura conjunta de tres grandes vías: logística, energética e informática; una interacción virtuosa entre las empresas, la sociedad y el gobierno, y la ampliación de los canales de financiación, es decir de los fondos, los créditos y los seguros. Con el propósito de elevar el valor agregado de los principales rubros de exportación de América Latina y el Caribe, nuestro gobierno estimula a las empresas chinas a invertir en la región y cooperar con los países que la integran en el procesamiento integral de productos energéticos, mineros y agrícolas, así como en la fabricación de maquinarias y materiales de construcción, la siderurgia, y las industrias química y de alimentos. Podemos explorar juntos la posibilidad de establecer zonas económicas especiales y polígonos industriales, como también entablar negociaciones encaminadas a facilitar el comercio y la inversión, entre otras cosas mediante tratados de libre comercio. En la Cumbre anuncié también la creación de un fondo especial de cooperación industrial entre China y la región, al que nuestro país aportará 30.000 millones de dólares, con el fin de respaldar la pronta materialización de nuestra cooperación en materia de capacidad productiva e inversiones. (Li 2016, 26-27)

No âmbito do Fórum também se realiza ações visando ampliar as conexões sociais e culturais entre a região e a China com a Cúpula Empresarial China-América Latina e Caribe, o Fórum de Intercâmbio de Think Tanks China-América Latina e Caribe, o Fórum de Partidos Políticos China-Celac e o Fórum de Amizade entre Sociedades Civis China-América Latina e Caribe. Este âmbito do soft power talvez seja o aspecto no qual a China encontrará mais dificuldade para ampliar a influência na região dada a predominância cultural e social dos Estados Unidos, muitas vezes reproduzidas e ampliadas sem qualquer controle estatal direto.

Ao analisar os desafios colocados pela ascensão da China para a América Latina e Caribe em um momento de desaceleração da economia chinesa, a Cepal (Li 20I6, I9) defende que "a construção de uma associação para o desenvolvimento entre a China e a América Latina seria benéfica para ambas as partes, mas para isso requer uma governança global". E, neste aspecto, aparece outra deficiência dos Estados latino-americanos, é a baixa capacidade de estatal para definir políticas e implementá-las adequadamente, o que acaba por ampliar o poder da própria China para definir as prioridades em termos de políticas e obras necessárias para o aprofundamento das relações com a América Latina. E, este aspecto desafia a saída proposta pela Cepal, modificar a natureza dos vínculos com a economia chinesa para reduzir a dependência 
da exportação de produtos primários. O surgimento deste vínculo dependeu mais dos fatores sistêmicos engendrados pelo crescimento chinês e das políticas do governo chinês do que ao resultado de políticas adotadas pelos países latino-americanos. Alguns não tinham a opção de exportar outro tipo de mercadoria, e, países com esta opção, como Brasil e Argentina, não foram capazes de formular políticas capazes de enfrentar os resultados gerados pela dinâmica chinesa e o mercado mundial.

Ainda que a China reitere insistentemente estar em um processo de desenvolvimento pacífico, seu crescimento já provocou resultados sistêmicos com a redistribuição do poder no âmbito econômico. E, no aspecto político, a aproximação com a América Latina parece consolidar um afastamento do princípio de Deng Xiaoping, tao guang yan hui (TGYH), "Somente nos tornaremos um grande poder político se mantivermos nosso baixo perfil (TGYH) e trabalhemos duro durante alguns anos, e nós teremos maior peso nos assuntos internacionais (Deng Xiaoping apud Chen e Wang 20II, I97). Hoje é inquestionável a presença política e econômica chinesa na América Latina, região de tradicional influência dos Estados Unidos. Portanto, a atuação chinesa não passa despercebida. Ainda sem expressão militar, é inegável a disposição chinesa para participar de uma disputa geopolítica e geoeconômica pela América Latina e Caribe.

\section{A Reação dos Estados Unidos}

Como examinado, a presença dos Estados Unidos na América Latina, em particular na América do Sul, foi caracterizada por dois momentos distintos depois do fim da Guerra Fria: a ofensiva dos anos I990 e o distanciamento da primeira década do século XXI. Este distanciamento permitiu uma expansão das iniciativas do Brasil, da América do Sul e o aumento da presença da China, fortalecendo uma dinâmica de parcerias intra e extrarregionais, baseadas na Cooperação Sul-Sul.

Diante deste contexto, que não se restringe à América do Sul, mas a todo o sistema internacional, sintetizado na premissa da multipolaridade e desconcentração de poder, representadas pela ascensão dos emergentes, os Estados Unidos investiram em um processo de contrarreação hegemônica. Inicialmente, um processo focado nos pilares estratégicos e que se amplia para uma dinâmica político-econômica.

Os primeiros passos começam no governo de W. Bush por meio de ações estratégicas, com foco na militarização do relacionamento hemisférico. Esta militarização soma-se a projetos já em andamento como o Plano Colôm- 
bia e a definição da Tríplice Fronteira como zona de risco, e engloba alterações no Comando Militar do Sul (USSOUTHCOM). Estas alterações referem-se à reativação da Quarta Frota do Atlântico Sul a partir de 2004, o aumento dos investimentos no USSOUTHCOM e a criação de um novo comando militar em 2008, com projeção sobre o continente africano e o Atlântico Sul (USAFRICOM). Em 2008, inicia-se uma nova guerra contra as drogas, a Iniciativa Mérida, na fronteira com o México.

A partir de 2009 , estas propostas estratégicas detém continuidade no governo de Barack Obama (2009/2016). Apesar de seu foco inicial na recuperação econômica, a gestão democrata intensifica a reação na América Latina e globalmente contra os emergentes, a despeito de seu discurso de engajamento positivo. Este discurso esteve presente na National Security Strategy de 20I0 (NSS, 20I0) quando estas nações, estando aí incluídas o Brasil foram definidas como novos centros de poder.

Em outras retóricas, Obama e altos oficiais do governo como a então Secretária de Estado Hillary Clinton criticam a projeção dos emergentes e seu padrão "imperialista” de Cooperação Sul-Sul. As acusações são duplas: primeiro, desestruturar a ordem multilateral a partir das pressões para a reforma da governança (defendida por Obama, mas sob novo padrão, mais gradual e menos profunda) e, segundo, explorar os países de menor pode relativo por seus recursos em uma relação assimétrica. A esta reação retórica, uma dinâmica prática se agrega a partir de 20II, condicionada pela recuperação econômica norte-americana que permite que o país passe da defensiva à ofensiva.

Algumas iniciativas merecem destaque. Nas Américas, os Estados Unidos apoiam a criação da citada Aliança do Pacífico, organismo direcionado ao livre comércio, sem pretensões político-estratégicas de integração regional, oferecendo um contraponto aos processos liderados pelo Brasil. A mesma tática de focar em negociações de cunho comercial, e que pressiona o Brasil e a China, tentando ocupar espaços no Atlântico Sul e no Pacífico de atuação destas potências ocorre no lançamento das conversações da Parceria Transpacífica (TPP) em 20Iı e da Parceria Transatlântica (TTIP) em 2013.

Em Outubro de 2015, o acordo comercial da TPP entrou em vigor sendo composto de Austrália, Brunei, Canadá, Chile, Estados Unidos, Japão, Malásia, México, Nova Zelândia, Peru, Singapura. Na oportunidade, esta iniciativa foi definida como o "maior acordo comercial do mundo". Mais uma vez, reproduz as ações norte-americanas de estabelecer acordos de livre comércio com nações com as quais possui forte interdependência via TLCs já em andamento ou projetos de integração como o NAFTA. Porém, o TPP não era apenas um acordo comercial, do qual se excluem os BRICS, mas também 
um tratado estratégico, por meio do qual existe (e está existindo) um reposicionamento de tropas militares. Tal reposicionamento visa pressionar China, Rússia e Índia, fazendo ponte com o USSOUTHCOM, o USAFRICOM e o Comando Militar do Pacífico (USPACOM).

Por sua vez, o TTIP, conhecido como "Tratado Bilateral Estados Unidos-União Europeia" continua suas negociações, realizadas de forma secreta. A área transatlântica já possui forte interdependência, e visa restringir o acesso dos emergentes aos mercados do norte. Tentativa similar de acordo já foi realizada, na época sem sucesso, entre I994-1995 quando se negociou um possível TAFTA (Área de Livre Comércio Transatlântica). Caso concluído, o TTIP, ao lado do TPP, não somente traz pressões reais sobre o Sul, mas igualmente sobre o sistema multilateral de negociações da OMC.

No entorno regional, Obama não avançou nenhuma proposta nova de zona hemisférica de livre comércio, mas em Dezembro de 20I4 anunciou uma das mais importantes mudanças no sistema interamericano: a retomada das relações diplomáticas com Cuba, peça tradicional da política da Guerra Fria. Tal retomada possui razões tanto internas quanto externas: o desejo de pressionar os grupos de interesse conservadores cubanos e se aproximar dos eleitores hispânicos de nova geração fortalecendo o partido democrata nesta base eleitoral em termos domésticos e conter o avanço sino-brasileiro na região em nível externo, rompendo o isolamento dos Estados Unidos. A luz desta retomada o Secretário de Estado John Kerry também anunciou o novo fim da Doutrina Monroe em 20I4.

Esta retomada esvazia parte das críticas aos norte-americanos na América Latina, em um momento de queda de liderança brasileira e venezuelana (em crise permanente desde a morte de Chávez). Além disso, prepara terreno para a futura presidência norte-americana que assumirá em 20I7, dar continuidade às ofensivas político-econômico-estratégicas, independente de ser republicana ou democrata.

No caso do relacionamento bilateral, a reaproximação pós-20I3 levou a citada visita de trabalho da Presidente Dilma aos Estados Unidos e a algumas concessões como a abertura do mercado de carne bovina a produtos brasileiros, o estabelecimento do Global Entry (visto especial para empresários), declarações de apoio mútuo e memorandos de entendimento variados (sendo o último de Abril de 2016 sobre infraestrutura). Em termos práticos, nada foi alterado, principalmente pela crise brasileira e a continuidade de pressões da oposição para um relacionamento bilateral preferencial em detrimento da política anterior globalista. Inclusive, a China continua, a despeito destas negociações, a principal parceira individual do país. Predomina aqui também o baixo perfil e enquanto isso os Estados Unidos, assim como a China, avançam 
no vácuo de poder brasileiro.

\section{Considerações Finais}

Ao longo destes primeiros anos do século XXI, a América do Sul se tornou um ator importante geopolítica e geoeconomicamente pela prioridade dada ao processo de integração regional, especialmente, pelos presidentes Lula, Néstor Kirchner e Hugo Chávez. Neste processo, o protagonismo brasileiro tanto em âmbito regional como global foi fundamental para gerar consensos e uma visão favorável sobre os efeitos de longo prazo da integração regional. Entretanto, desde o início do governo Dilma Rousseff, este processo refluiu. Inicialmente, porque a política externa deixou de ser uma prioridade na agenda presidencial, provocando uma diminuição do protagonismo brasileiro, adotou-se uma postura de baixo perfil. Este processo foi se aprofundando ao longo dos anos subsequentes na medida em que o Brasil mergulhava na crise política e econômica. Com a crise e a priorização dos problemas internos, houve um esvaziamento da agenda integracionista e o poder de atração do Brasil sobre seus vizinhos diminuiu.

Neste contexto, ganhou relevância a Aliança do Pacífico, que indicava exatamente o protagonismo dos Estados Unidos e da China na região. Em função da prioridade dada à questão do terrorismo e do fracasso das negociações da ALCA, os Estados Unidos se afastaram relativamente da América do Sul o que deu oportunidade em primeiro lugar para o protagonismo brasileiro e para a crescente presença chinesa. Com o esvaziamento da liderança brasileira, China e Estados Unidos estão reassumindo este protagonismo. E as recentes mudanças de governo com a derrota eleitoral ou o enfraquecimento político dos governos aumentam o tamanho do desafio colocado diante da América do Sul. Ainda é possível trabalhar por políticas autônomas de desenvolvimento alicerçadas na integração regional que permitam um relacionamento mais soberano tanto com os Estados Unidos como com a China. Entretanto, se os projetos de integração e as tentativas de concertação política forem abandonados, o novo padrão estrutural das relações econômicas e políticas da América do Sul com a China e os Estados Unidos tendem a se consolidar e as mudanças serão muito mais custosas, e os Estados da região, e mesmo o Brasil, podem se tornar meros peões no jogo de xadrez do poder de China e Estados Unidos. 


\section{REFERÊNCIAS}

Amorim, Celso. 2015. Teerã, Ramalá e Doha- memórias de uma política externa ativa e altiva. Rio de Janeiro: Ed. Benvir.

Chen, Dingding, e Wang, Jianwei. 20II. "Lying low no more? China's new thinking on the Tao Guang Yang Hui strategy. China: an international journal. 9(2): 195-216.

Freyre, Gilberto. 20II. China Tropical: e outros escritos sobre a influência doOriente na cultura luso-brasileira. São Paulo, Global.

García, Alan. 2013. Confucio y la globalización: comprender China y crecer con ella. Lima, Titanium Editores.

IIRSA 20I6. http://www.iirsa.org

Li, Keqiang. 20i6. Crear juntos un nuevo porvenir de la Asociación de Cooperación Integral China-América Latina y el Caribe. In: CEPAL. Reflexiones sobre el desarrollo em América Latina y el Caribe: Conferencias Magistrales 2015. Santiago, Cepal.

MDIC. 20I6. "Comércio Bilateral Brasil-China." Série Histórica. Acesso: or de Junho. http://www.mdic.gov.br/index.php/comercio-exterior/estatisticas-de-comercio-exterior/series-historicas.

MDIC. 20I6. "Comércio Bilateral Brasil-Estados Unidos." Série Histórica. Acesso em or de Junho. http://www.mdic.gov.br/index.php/comercio-exterior/estatisticas-de-comercio-exterior/series-historicas.

NSS. 20I5. "National Security Strategy. The White House." Acesso em io de Maio http://nssarchive.us/national-security-strategy-2010/.

OCDE/CEPAL/CAF. 20I6, Perspectivas económicas de América Latina 2016: Hacia una nueva asociación com China, OECD Publishing, Paris. Acesso em 30 de março. <http://dx.doi.org/10.1787/9789264246348-es>.

Pecequilo, Cristina Soreanu. 2013. Os Estados Unidos e o Século XXI. Rio de Janeiro: Ed. Elsevier.

Visentini, Paulo Fagundes. 2013. A projeção internacional do Brasil-1930/2012. Rio de Janeiro: Ed. Elsevier.

WTO. 2015a. International Trade Statistics 2015. Genebra, WTO.

WTO. 20I5b. Trade profiles 2015. Genebra, WTO. 


\section{RESUMO}

A primeira década do século XXI foi caracterizada pela ação do Brasil na América do Sul. Porém, desde 20II, houve o recuo dos investimentos estratégicos, políticos e econômicos do país na integração, permitindo o avanço dos Estados Unidos e da China. O objetivo do artigo é analisar este contexto.

\section{PALAVRAS-CHAVE:}

China; Estados Unidos; Política Externa Brasileira.

Recebido em o7 de junho de 2016. Aprovado em 27 de julho de 2016. 